\title{
The Impact Of Covid-19 Pandemic on Systematic Risk Of S\&P 500 Sectors: A Wavelet Power Spectrum Analysis
}

\author{
Umut UYAR ${ }^{1} \odot$, Sinem Güler KANGALLI UYAR ${ }^{2} \odot$
}

\begin{abstract}
Investors reacted with panic and fear to the Coronavirus (COVID-19) pandemic and they created financial fluctuations. The aim of this study is to examine the volatility levels of S\&P500 sector portfolios' systematic risks in terms of different investment horizons. We employed the wavelet approaches that allow for analyzing the behavior of time series both jointly at the time and frequency spaces. Thus, we observed the variation of financial beta coefficients, and the volatility levels of systematic risks over different investment horizons by sectors. Daily returns of 386 stocks from eleven sectors and S\&P500 index was used for the period of January 2005 and July 2020. The findings of the study show that the systematic risks of sectors vary over different investment horizons. This means that the sensitivity of sectors to the daily movements of the market change at various time scales. Moreover, the volatility levels of systematic risks of each sector change over different investment horizons during the pandemic period. The results show that investors in the S\&P 500 ignore the COVID-19 at the beginning, however, they reacted with panic during the pandemic period. In this respect, the findings provide supporting evidence on behalf of the Prospect Theory.
\end{abstract}

Keywords: COVID-19 pandemic, Wavelet multi-scaling, Wavelet power spectrum analysis, Systematic risk, S\&P500

\section{INTRODUCTION}

In finance, there are widely accepted assumptions about financial markets and investors. Two of those are that the investors are rational and the information about securities fully reflects prices. Those assumptions are in regard to the Efficient Market Hypothesis (EMH) proposed by Fama (1970). Fama classified the financial markets into three groups are about weak, semi-strong, and strong. A strong form of efficiency is considered impossible in the real world. Because this form assumes that the information fully reflects prices and there is no irrational investor in the market (Grossman and Stiglitz, 1980). Thus, the weak and semi-strong forms of the EMH are assumed to be applicable in practice (Karp and Van Vuuren, 2019). Despite the widespread use of the $\mathrm{EMH}$, a large and growing literature criticizes the theory (Jensen, 1978; Shiller et.al. 1984; Black, 1986; Bernard et.al. 1994; Kahneman and Riepe, 1998; Shleifer, 2000; Griggs, 2002; Glen 2005; Jarrett and Kyper, 2006; Aygo- ren 2008; Robinson, 2013; Xu et.al. 2018; Karp and Van Vuuren, 2019). Especially, the rationality assumption for investors does not match with the real world. Most researchers examined this phenomenon for nearly half of the century. The pioneering researchers Kahneman and Tversky (1979) stated that investors are not rational when they faced a risky choice leading to losses, peculiarly. Thus, this irrational behavior of investors creates asymmetric market reactions that people react differently between potential losses and potential gains. Those reactions are based on emotions such as panic/ courage and fear/greed. When panic or fear occurs in the market, unexpected drops might be observed; on the contrary, courage or greed can create unexpected peaks in the market. In financial markets, financial crises might cause unexpected drops and peaks.

Financial markets suffered many kinds of crises in history. Several crises affect all over the world, while some of them had limited effects on countries or 
continents. The most recent ones are the Mortgage Crisis and the European Debt Crisis. The mortgage crisis started in the financing sector of the USA, however, it spread out all over the world and created high volatiles. After the mortgage crisis, the European debt crisis broke out in several European countries and it also created high volatiles in financial markets as well as real markets. Both crises have common features such as the existence of irrational investors, and price fluctuations due to emotional trade orders. Those crises gave a real-world example to researchers that investors react asymmetrically when an extraordinary circumstance occurred in the market.

At the end of December 2019, a new potential crisis came up from China, this time, the source of the crisis was in health. Coronavirus Disease (COVID-19) infected Asia, Europe, and North America, rapidly. The disease became a pandemic in the short-term. Hundreds of thousands of people are still suffering or they passed away. Even though it is an outbreak, it has major impacts on financial markets, as well. The effect of COVID-19 on financial markets can be considered in two groups: First, when the World Health Organization announced that it is a pandemic and the record number of cases and deaths had been seen in Europe, irrational investors started trading with panic and fear. Therefore, the COVID-19 caused to high volatile movements in financial markets. Second, the lockdown decisions of governments in different countries created uncertainty over demand drives, and commodity prices down. As a result of this circumstance, the perceived risk level of high debt ratio firms increased. This status can be explained with a chain relationship between demand, production, and revenue. While the uncertainty of demand causes stress on the production of goods and services, the surplus of supply leads to a decrease in revenue and profit. Thus, firms may not pay back their liabilities when there is a long quarantine period. With the breakdown of the chain relationship, several firms may be faced with bankruptcy. In conclusion, investors face rising risks in this pandemic time. The average debt ratios for the last six quarters of eleven S\&P 500 sectors which are shown in Table 1 can be considered as indicators of those rising risks.

According to Table 1, all sectors have average debt ratios over 50\% except for Energy. Moreover, three of them (Utilities, Consumer Discretionary, and Financials) have the highest debt ratios. Therefore, investors who invest in those three sectors might face a high risk of bankruptcy when a crisis strike.

The motivation of this study is based on the volatility levels of S\&P500 sectors. It is clear that there are fluctuations in returns, however, the impact of the pandemic, which is the source of those fluctuations, on systematic risks of sectors needs to be explained. The aim of this study is to examine the volatility levels of S\&P500 sector portfolios' systematic risks in terms of different investment horizons. For this aim, we employed the wavelet multi-scaling approach and the wavelet power spectrum analysis. The data source is Bloomberg Professional Terminal and the dataset constructed with the S\&P500 stock returns for the period of January 2005 and July 2020 includes the COVID-19 pandemic crisis. Thus, we can observe the behavior of systematic risk over different investment horizons before and during the COVID-19 pandemic.

Table 1: The average debt ratios of S\&P500 sectors

\begin{tabular}{llllllll}
\hline Sectors & Q3-2018 & Q4-2018 & Q1-2019 & Q2-2019 & Q3-2019 & Q4-2019 & Average \\
\hline Communication Services & $60.36 \%$ & $65.96 \%$ & $62.91 \%$ & $61.97 \%$ & $61.30 \%$ & $61.32 \%$ & $62.30 \%$ \\
\hline Consumer Discretionary & $72.02 \%$ & $73.63 \%$ & $74.44 \%$ & $76.38 \%$ & $77.16 \%$ & $76.86 \%$ & $75.08 \% *$ \\
\hline Consumer Staples & $67.81 \%$ & $68.66 \%$ & $68.34 \%$ & $68.31 \%$ & $68.54 \%$ & $68.55 \%$ & $68.37 \%$ \\
\hline Energy & $48.02 \%$ & $47.78 \%$ & $48.99 \%$ & $49.56 \%$ & $50.62 \%$ & $52.31 \%$ & $49.55 \%$ \\
\hline Financials & $79.53 \%$ & $79.74 \%$ & $79.90 \%$ & $79.54 \%$ & $79.49 \%$ & $79.47 \%$ & $79.61 \% *$ \\
\hline Health Care & $54.22 \%$ & $54.51 \%$ & $55.02 \%$ & $55.25 \%$ & $56.07 \%$ & $56.49 \%$ & $55.26 \%$ \\
\hline Industrials & $61.37 \%$ & $62.23 \%$ & $62.53 \%$ & $62.62 \%$ & $63.00 \%$ & $62.87 \%$ & $62.44 \%$ \\
\hline Information Technology & $64.10 \%$ & $63.53 \%$ & $64.19 \%$ & $64.49 \%$ & $62.37 \%$ & $61.91 \%$ & $63.43 \%$ \\
\hline Materials & $60.83 \%$ & $60.29 \%$ & $60.26 \%$ & $60.17 \%$ & $59.78 \%$ & $60.06 \%$ & $60.23 \%$ \\
\hline Utilities & $56.94 \%$ & $56.83 \%$ & $57.33 \%$ & $57.58 \%$ & $58.09 \%$ & $58.14 \%$ & $57.49 \%$ \\
\hline
\end{tabular}

* indicates three sectors which have the highest debt ratios 
The structure of the study is as follows. The second section briefly describes the theoretical framework of CAPM and the next section introduces methodology. The fourth section conveys information about the data and presents descriptive statistics of the dataset. The fifth section provides empirical evidence from the analysis. Finally, some remarkable inferences related to findings are made in the conclusion section.

\section{THE FRAMEWORK OF CAPM}

There are various investors in terms of having different investment horizons in the financial markets. Those investors might be intraday investors, day investors, short-term and long-term traders. Intraday investors execute trades within a given day whereas day investors may take their positions overnight. Short-term traders respond to market information within a shortterm horizon while long-term traders interest in price fundamentals which drives all trends in the financial market. Consequently, all activities of those investors cause to heterogeneous market activities and generate market prices. According to In and Kim (2013), the true dynamic relationships between the various aspects of market activity could be only captured when the market prices are decomposed to different timescales. This viewpoint brings the question to mind how stock returns respond to different risk factors across different timescales or investment horizons. More clearly, how the beta in the Capital Asset Pricing Model (CAPM) (Equation 1) that indicates the stock return-market risk relationship changes over different timescales?

$R_{i}=R_{f}+\beta_{i}\left(R_{m}-R_{f}\right)+\varepsilon$

$R_{i} \quad$ :The return of $\mathrm{i}^{\text {th }}$ financial asset

$R_{f} \quad$ :The risk-free return of market

$\beta_{i} \quad$ : Financial beta coefficient of $\mathrm{i}^{\text {th }}$ asset

$R_{m}$ :The return of market index

$\varepsilon \quad:$ Error term

Some studies on beta estimations scrutinized the variability of beta based on different time intervals. One of the pioneer studies Levhari and Levy (1977) indicated that when the time horizon is selected as shorter than the true one, the beta estimates will be biased. Cohen et al. (1986), presented some findings on the sensitiveness of beta estimations according to different data frequencies. Similarly, Handa et al (1989) showed that beta estimates vary by data frequency for the same stock. Handa et al (1993) found out the CAPM is valid for yearly return intervals while it is not for monthly ones by using portfolio returns on NY-
SE-AMEX stocks. Brailsford and Faff (1997) examined the validity of CAPM for daily, weekly, and monthly returns in the Australian stock market and report that the CAPM is supported especially for weekly and then monthly return intervals while it is rejected for yearly ones. Gençay et al. (2003) investigated the impact of different data frequencies on beta estimation by choosing a stock from the US market. They reported that the number of observations decreases towards the low data frequencies and this results in information loss. Gençay et al. (2003) proposed a new approach based on the wavelet analysis to consider the sensitiveness of beta estimations to different time timescales. This approach provides a natural platform to decompose a time series measured at the highest possible frequency into different timescales. Their findings provide some evidence that the relationship between the return of a portfolio and its beta becomes stronger as the timescale increases. In a similar manner, Gençay et al. (2005) used the wavelet analysis to estimate the beta or systematic risk of an asset for different stock markets such as the US, Germany, and the UK. Their empirical results show that the return-beta relationship is a multiscale phenomenon and the relationship is stronger at long timescales compared to short timescales.

In this study, we aim to investigate the systematic risks across different timescales by the wavelet approach. The analysis period of January 2005 and July 2020 includes the COVID-19 pandemic crisis. In this way, we can observe the behavior of systematic risk over different investment horizons before and during the COVID-19 pandemic. It is easy to understand that there are fluctuations in returns during the pandemic period, however, the impact of those fluctuations on systematic risks needs to be explained. Therefore, we also examine the volatility levels of systematic risk based on the wavelet approach.

\section{METHODOLOGY}

The short-term and long-term concepts are crucial in the modeling of financial decisions. Some investors operating in the market for stocks may have a long investment horizon and may execute trading according to market fundamentals while some others may carry out trading with shorter time-horizons such as days or weeks. The wavelet approach provides a natural tool to the finance discipline which timescale is substantial, by decomposing the data into different timescales. Thus, investigation of the relationships between variables at the disaggregated level rather than the aggregate 
level will provide new insights into the analysis. There are a few more reasons for using the wavelet approach instead of a standard time series technique. One of them is that it allows for analyzing nonstationary data without applying any transformation such as differencing or detrending (Gallegati et al., 2006). The wavelet approach also allows for analyzing the behavior of time series both jointly at the time and frequency spaces, and thus, it can reveal different properties of the original time series. Furthermore, the nonparametric nature of wavelets considers potential nonlinear relationships without losing information (Schleicher, 2002). The superiorities of the wavelet approach to the standard time series techniques prompt to use the wavelet approach to examine the behavior of betas or systematic risk of portfolios. In this section, we will explain different wavelet approaches that are used in the study.

\subsection{Wavelet Approach}

The various applications of the wavelet approach in economics and finance have rapidly increased over the recent 20 years. Some studies play an important role in escalating the other empirical studies in economics and finance related to the wavelet approach (Ramsey and Lampart, 1988; Percival and Walden, 2000; Ramsey, 1999; 2002; Gençay et al., 2001;2002; 2003;2005; Schleicher, 2002; Kim and In, 2003; Capobianco, 2004; Shik Lee, 2004; Connor and Rossiter, 2005; Crowley and Lee, 2005; Crowley, 2007). Following these studies, we investigate the evolution of betas or systematic risks in the CAPM with respect to time and show at which frequencies the betas are active.

In wavelet analysis, appealing characteristics of time series at different frequencies (low and high) and different time horizons (short-term and long-term scales) might be revealed by applying the wavelet transform to time series. The wavelet transforms are generally classified into two groups such as discrete and continuous. Discrete wavelet transform (DWT) reduces the fluctuations in the data and provides a smoother data view, thus providing the inference about the whole data based on the components of the data divided into different timescales. On the other hand, continuous wavelet transform (CWT) reveals detailed features of the data (Grinsted et al., 2004). Moreover, it is not necessary to detect the structural breaks since CWT can capture all the dynamics of the financial time series (Saiti et al., 2016). In CWT, the number of timescales is directly determined according to the length of data whereas it is an issue in DWT (Altarturi et al., 2016). In this study, we apply different wavelet approaches based on DWT and CWT. Therefore, we use both DWT and CWT.

\subsection{Wavelet Multiscaling Analysis}

Wavelet multiscaling analysis (WMA) provides decomposing the time series into different timescales of variations using the wavelet transform. For wavelet transforms, there are two types of wavelet functions defined as father $(\phi)$ and mother wavelet $(\psi)$ functions. Father wavelet denotes the low-frequency components and the smooth part of the original data, while the mother wavelet denotes the high-frequency components of the original data, so it reflects the details about the data. The definition of father and mother wavelet functions are as follows:

$$
\begin{aligned}
& \phi_{j, k}(t)=2^{-\frac{j}{2}} \phi\left(2^{-j} * t-k\right), \\
& j=1,2, \ldots, J ; \quad k=0,1, \ldots, 2^{j}-1 \\
& \psi_{j, k}(t)=2^{-\frac{j}{2}} \psi\left(2^{-j} * t-k\right), \\
& j=1,2, \ldots, J ; \quad k=0,1, \ldots, 2^{j}-1
\end{aligned}
$$

where $j=1,2, \cdots, J$ is the scaling parameter in a J-level decomposition and $\mathrm{k}$ is a location parameter. Scaling parameter controls the length of the wavelet and the location parameter determines the position of the wavelet. The scaling parameter from 1 to $J$ indicates that the time series is decomposed into $\mathrm{J}$ different time scales and $J$ is the highest level of timescale.

$\phi($.$) and \psi($.$) are real-valued functions defined over$ real axis $(-\infty,+\infty)$ and they provide the following normalization conditions:

$$
\begin{aligned}
& \int_{-\infty}^{+\infty} \phi(t) d t=1 \\
& \int_{-\infty}^{+\infty} \psi(t) d t=0
\end{aligned}
$$

A wavelet representation of a time series $x(t)$ in $L^{2}(R)$ can be given by,

$$
x(t)=\sum_{k=0}^{2^{j}-1} s_{J, k} \phi_{J, k}(t)+\sum_{j=1}^{J} \sum_{k=0}^{2^{j}-1} d_{j, k} \psi_{j, k}(t)
$$

where $s_{J, k}=\int_{-\infty}^{+\infty} x(t) \phi_{J, k}(t) d t$ and $d_{j, k}=\int_{-\infty}^{+\infty} x(t) \psi_{j, k}(t) d t$ with $j=1,2, \ldots, J . s_{J, k}, d_{J, k}, \ldots, d_{1, k}$ are the wavelet transform coefficients. More specifically, $s_{J, k}$ are the coefficients for the father wavelet at the highest scale and known as the smooth coefficients that capture the trend. $d_{j, k}$ are the detailed coefficients obtained from 
the mother wavelet at all scales from 1 to $\mathrm{J}$ and can capture the higher frequency oscillations.

The expression in Equation (7) can be demonstrated in a more compact way:

$$
\begin{aligned}
& x(t)=S_{J}(t)+\sum_{j=1}^{J} D_{j}(t) \\
& \text { where } S_{J}(t)=\sum_{k=0}^{2^{j}-1} S_{J, k} \phi_{J, k}(t) ; \\
& D_{j}(t)=\sum_{k=0}^{2^{j}-1} d_{j, k} \psi_{j, k}(t) \text { with } j=1,2, \ldots, J .
\end{aligned}
$$

This expression includes the components of $x(t)$ that are decomposed into different timescales and it is defined multiscale decomposition. $S_{J}(t)$ is the component at the highest timescale and indicates the smooth part of the data. $D_{j}(t)$ captures cyclical movements of $2^{j}-2^{j+1}$ periods. Thus, $D_{1}(t), D_{2}(t), \ldots, D_{J}(t)$ are details that include oscillations in the data at 2-4, $4-8, \ldots, 2^{J}-2^{J+1}$ timescales, respectively. Herein, small values of $j$ correspond to low-scale (high-frequency) components of $x(t)$, whereas large values of $\mathrm{j}$ correspond to high-scale (low-frequency) components of $x(t)$ (Habimana, 2019: 91).

\section{Selection of Wavelet Transform}

In the wavelet multiscaling analysis, it is important to select an appropriate wavelet transform. This analysis is performed based on DWT. There is one more discrete wavelet transform called the maximal overlap discrete wavelet transform (MODWT) which is a non-orthogonal variant of DWT and has some superiorities over DWT. Unlike the classical DWT, MODWT can deal with any sample size regardless of whether dyadic ${ }^{3}$ or not and MODWT provides at each scale a number of coefficients equal to the length of the original time series. In contrast to the DWT, the detail and smooth coefficients are invariant with respect to shifts in the original time series. Moreover, MODWT produces a more asymptotically efficient wavelet variance estimator than DWT (Percival and Mofjeld, 1997). In this study, we use MODWT for the wavelet multiscaling analysis because of its advantages over DWT. The detail and smooth coefficients based on MODWT are obtained using the Pyramid algorithm (Mallat, 1989).

\section{Selection of Wavelet Filter and Length}

After determining the appropriate wavelet transform, it is also required to choose a suitable wavelet filter. The most known wavelet filters are Haar filter of length 2, Daubechies ("D"), and Least-Asymmetric ("LA") filters of length 4-8. Most researchers opt for either the wavelet filters of $D(4), D(8), L A(4)$, or $L A(8)$ in finance. Gençay et al. $(2003,2010)$ state that the LA (8) wavelet is an appropriate choice to analyze financial time series. On the other hand, Crowley (2007) expresses that the selection of another wavelet filter has a quite limited impact on the distribution of the variance of time series across different timescales. However, he states that the length of the wavelet filter should be 8 for financial series and volatile economic series. According to Masset (2015), some properties of wavelet filters are determinative in the selection of wavelet filters. Those properties are symmetry, orthogonality, smoothness, and the number of vanishing moments. Symmetric wavelet filters ensure that the original time series and its filter coefficients will be aligned. Even though most wavelet filters are not symmetric except for the Haar wavelet, MODWT provides the appropriate conditions. The orthogonality feature ensures that wavelet coefficients involve different information and allows for the wavelet decomposition to preserve the variance of the original time series. In the case of the original time series are very smooth, then a smooth wavelet might be preferred. Haar wavelet is the least smooth wavelet, and so, appropriate for the analysis of a pure jump process. The number of vanishing moments provide us to make an inference on the ability of the wavelet to consider the behavior of the time series. If an original time series has a polynomial structure with order q, then the wavelet transform will be able to accurately account for this polynomial structure only if it has $q$ vanishing moments. In other words, if the selected wavelet filter does not reflect the underlying features of data, then the wavelet multiscaling analysis will be inefficient. The last two features are not only related to the wavelet filter but also on its length. As the length of the wavelet filter increases, a better fitting of data can be obtained. However, this increases the effect of boundary coefficients that is, longer wavelets produce more outliers at the endpoints of time series than shorter filters, especially at the lower scales. Therefore, there is a trade-off relationship between properties and length. The LA(8) can tolerate the effect of boundary conditions and also produces relatively smooth and uncorrelated wavelet coefficients (Cornish et al., 2006; Gençay et al., 2002).

\footnotetext{
${ }^{3}$ The term of dyadic means that the sample size is divisible by $2^{J}$.
} 


\section{Wavelet Power Spectrum Analysis}

The wavelet power spectrum analysis is performed based on CWT. Given a time series $\mathrm{x}(\mathrm{t}) \in L^{2}(R)$, its CWT with respect to the mother wavelet, $\psi(t)$, a function of two parameters, $W_{x}(u, s)$ can be expressed by:

$$
W_{x}(u, s)=\int_{-\infty}^{+\infty} x(t) \frac{1}{\sqrt{s}} \psi\left(\frac{t-u}{s}\right) d t,
$$

where, $\frac{1}{\sqrt{s}}$ is a normalization factor to assure that wavelet transforms are comparable across different timescales (Rua and Nunes, 2009: 633). $s$ is a scaling parameter that controls the length of the wavelet and $u$ is location parameter providing the exact position of the wavelet (Percival and Walden, 2000). To be a mother wavelet, $\psi(t)$ should meet some conditions: it must have zero mean, $\int_{-\infty}^{+\infty} \psi(t) d t=0$; its square integrates to unity, $\int_{-\infty}^{+\infty} \psi^{2}(t) d t=1$ which ensures that $\psi(t)$ is limited to an interval of time; and the admissibility condition, $C_{\psi}=\int_{0}^{+\infty} \frac{|\psi(f)|^{2}}{f} d f<\infty$ oshould be provided, where $\psi(f)$ is the Fourier wavelet transformation of $\psi(t)$. This condition allows the reconstruction of a time series $x(t)$ from its CWT through the following formula:

$$
\begin{aligned}
& x(t)=\frac{1}{C_{\psi}} \int_{0}^{\infty}\left[\int_{-\infty}^{+\infty} W_{x}(u, s) \psi_{u, s}(t) d u\right] \frac{d s}{s^{2}}, \\
& s>0 .
\end{aligned}
$$

There are many different mother wavelet functions such as Morlet, Mexican Hat, Haar, Daubechies, and each of them has its own characteristics. The Morlet wavelet is the most commonly used because it has optimal joint time-frequency concentration (Aguiar-Conraria and Soares, 2011). The definition of Morlet wavelet can be given by:

$$
\psi^{M}(t)=\frac{1}{\pi^{1 / 4}} e^{i w_{0} t} e^{-t^{2} / 2}
$$

where, $w_{0}$ is the central frequency of the wavelet and is generally set to 6 in the literature. Thus, the optimal balance in time-frequency space is achieved (Aloui and Hkiri, 2014).
An important feature of CWT is energy preservation and this means that the sum of the variances of each time scale is equal to the variance of the original time series. The variance of time series reconstructed by CWT can be expressed using this feature as follows:

$$
\|x\|^{2}=\frac{1}{C_{\psi}} \int_{0}^{\infty}\left[\int_{-\infty}^{+\infty}\left|W_{x}(u, s)\right|^{2} d u\right] \frac{d s}{s^{2}} .
$$

This expression is employed for the wavelet power spectrum (WPS) analysis. The wavelet power can be defined as a measure of the local volatility or the local variance for $x(t)$ at time-frequency space. The findings of WPS analysis are interpreted through the plots.

Plots of the wavelet power spectrum reveal interesting structures, like dominant timescales of variation in the data or characteristic scales (Gallegati et al., 2014).

\section{DATA}

The preparation process of the dataset contains two stages. At the first stage, daily returns of 386 stocks and index returns were gathered from eleven sectors of S\&P500 for the period of January 2005 and July 2020. The assets were selected from the stocks which trade continuously and have not to include missing values.

After gathering the return data, sector portfolios were constructed giving equal weights to each sector stock. The output of the first stage is eleven sector portfolio time series for the data period. At the second stage, portfolio beta coefficients over the last 100 days which present the systematic risk are calculated. To do so, the first 100 observations are used to calculate the betas and the computations are movingly repeated. The output of the second stage is the sector-based daily beta time series from May 2005 to July 2020. In the first and second stages, the dataset was obtained from the Bloomberg Professional Terminal. The descriptive statistics for sector-based portfolio returns and beta time series are given in Table 2 and Table 3. 
Table 2: Descriptive statistics of sector-based portfolio returns

\begin{tabular}{lcccccccc}
\hline & Mean & Median & Maximum & Minimum & Std. Dev. & Skewness & Kurtosis & JB Stat. \\
\hline Communication Services & 0.000314 & 0.000375 & 0.126073 & -0.10600 & 0.013234 & -0.26566 & 14.37999 & 21939 \\
Consumer Discretionary & 0.000243 & 0.000324 & 0.148131 & -0.17627 & 0.015612 & -0.50378 & 16.46060 & 30799 \\
Consumer Staples & 0.000313 & 0.000361 & 0.078645 & -0.09226 & 0.009250 & -0.25456 & 13.78624 & 19710 \\
Energy & 0.000047 & 0.000000 & 0.185770 & -0.35297 & 0.021537 & -1.49628 & 29.53355 & 120524 \\
Financials & 0.000105 & 0.000335 & 0.137149 & -0.16346 & 0.018816 & -0.50518 & 17.90968 & 37750 \\
Health Care & 0.000459 & 0.000559 & 0.108202 & -0.10785 & 0.011836 & -0.55745 & 12.52912 & 15559 \\
Industrials & 0.000343 & 0.000550 & 0.116874 & -0.11534 & 0.014449 & -0.45488 & 11.96237 & 13718 \\
Information Technology & 0.000417 & 0.000554 & 0.109648 & -0.14017 & 0.014252 & -0.38035 & 12.31058 & 14751 \\
Materials & 0.000255 & 0.000538 & 0.111732 & -0.12429 & 0.015156 & -0.59108 & 12.53940 & 15619 \\
Real Estate & 0.000202 & 0.000472 & 0.184479 & -0.20279 & 0.019181 & -0.46953 & 21.79700 & 59876 \\
Utilities & 0.000206 & 0.000603 & 0.122441 & -0.13705 & 0.012085 & -0.16057 & 21.07477 & 55242 \\
SPX Index & 0.000246 & 0.000391 & 0.109572 & -0.12765 & 0.012317 & -0.56334 & 17.83681 & 37425 \\
\hline
\end{tabular}

Table 3: Descriptive statistics of sector-based betas

\begin{tabular}{lcccccccc}
\hline & Mean & Median & Maximum & Minimum & Std. Dev. & Skewness & Kurtosis & JB Stat. \\
\hline Communication Services & 0.978698 & 0.977967 & 1.298431 & 0.677309 & 0.090011 & 0.600775 & 4.261278 & 500 \\
Consumer Discretionary & 1.109495 & 1.092378 & 1.772549 & 0.766241 & 0.148746 & 1.022775 & 5.033220 & 1371 \\
Consumer Staples & 0.645192 & 0.643165 & 0.898624 & 0.311774 & 0.113286 & -0.03104 & 2.541526 & 35 \\
Energy & 1.253066 & 1.278599 & 2.175671 & 0.372137 & 0.241197 & 0.00000 & 3.453950 & 78 \\
Financials & 1.215208 & 1.180257 & 2.188702 & 0.840094 & 0.241666 & 1.366538 & 5.588289 & 2336 \\
Health Care & 0.931627 & 0.952272 & 1.215997 & 0.601696 & 0.123650 & -0.52289 & 3.090068 & 181 \\
Industrials & 1.138834 & 1.136317 & 1.654646 & 0.913439 & 0.116442 & 0.797318 & 4.605765 & 844 \\
Information Technology & 1.155720 & 1.116662 & 1.954910 & 0.890986 & 0.159388 & 1.922459 & 8.522592 & 7467 \\
Materials & 1.135597 & 1.132073 & 1.513311 & 0.843245 & 0.115045 & 0.302336 & 3.218869 & 68 \\
Real Estate & 0.959628 & 0.944488 & 2.367097 & 0.251386 & 0.396437 & 0.891957 & 4.135503 & 737 \\
Utilities & 0.598561 & 0.625846 & 1.251936 & -0.294540 & 0.259816 & -0.246570 & 2.992353 & 40 \\
\hline
\end{tabular}

There are some remarkable findings in Table 3. The mean of beta coefficients as a systematic risk indicator differs among the sectors. In real estate and utilities sectors, while the means of beta coefficients lower than 1 , they have high standard deviations. When a beta lower than 1 generally means that the asset is less sensitive to the movements of the market. Thus, those sectors are less sensitive to the daily movements of the market, however, the systematic risks of the sectors are not stable. When a crisis strikes the market, it is expected that the impact of crisis might be high in those sectors. Moreover, the reason for that the real estate sector has the highest standard deviation might be the mortgage crisis. On the other side, in energy and financial sectors, while the means of beta coefficients are greater than 1, they have high standard deviations. It means that those sectors are more sensitive to the daily movements of the market and not stable in terms of systematic risks. Those sectors might be evaluated as high risky sectors for investors.

\section{EMPIRICAL FINDINGS}

In this section, firstly, we investigate the return series of each S\&P 500 sector between January 2005 and July 2020 (Figure 1). Return is a fundamental indicator of financial analysts. Therefore, our starting point is the return analysis while investigating the impact of the pandemic on financial markets. Secondly, we employ the wavelet multi-scaling approach to estimate beta coefficients for each S\&P 500 sector over different timescales (Figure 2). Finally, we apply the wavelet power spectrum (WPS) analysis for the sector-based daily beta time series (the systematic risks of each sector). The findings of WPS analysis are presented in Figure 3. 
Communication Services

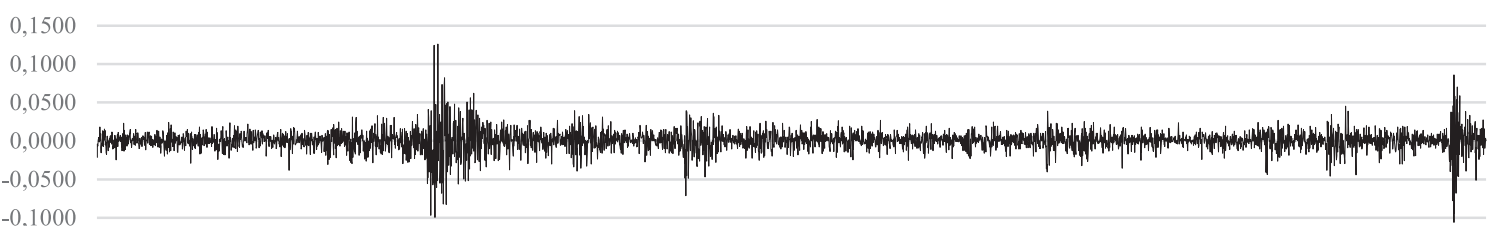

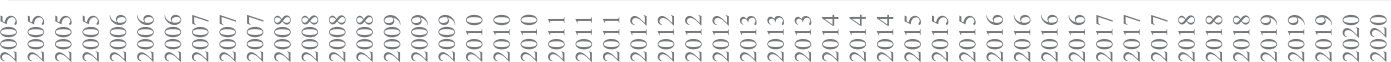

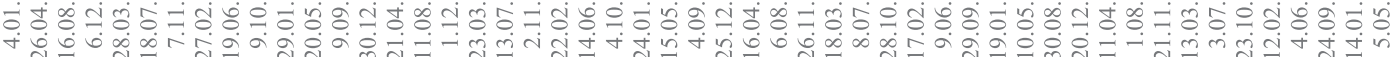

Consumer Discretionary

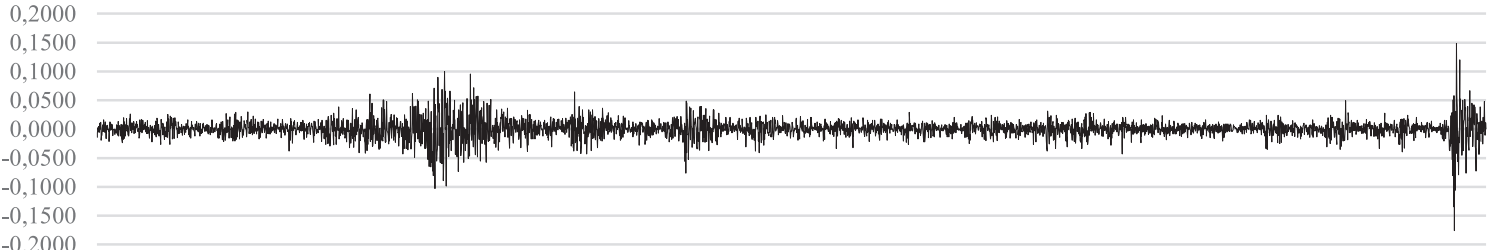

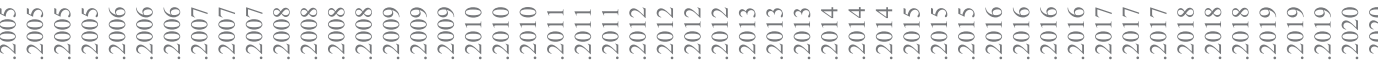

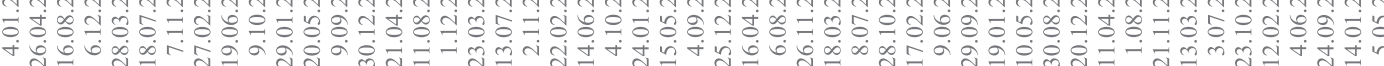

Consumer Staples

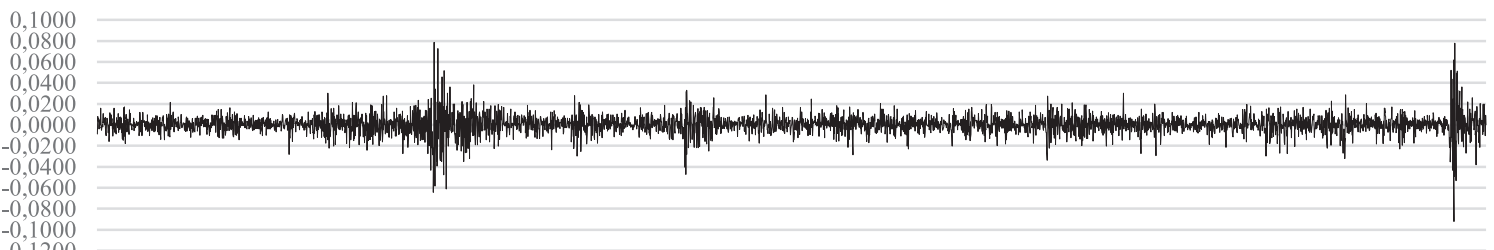

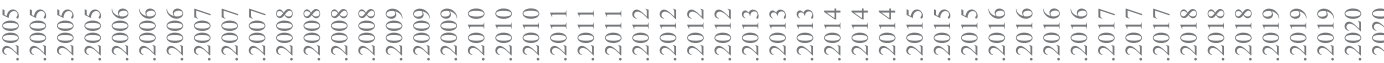

б

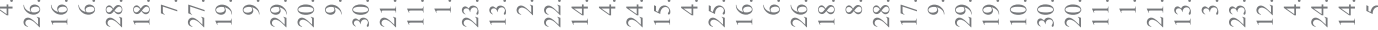

Energy

0,3000

0,2000

0,1000

0,0000

0,1000

$-0,2000$

$-0,3000$

$-0,4000$

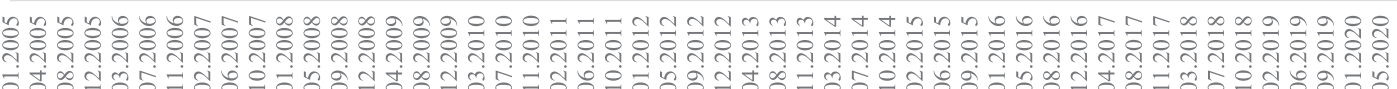

+ 0.0000 


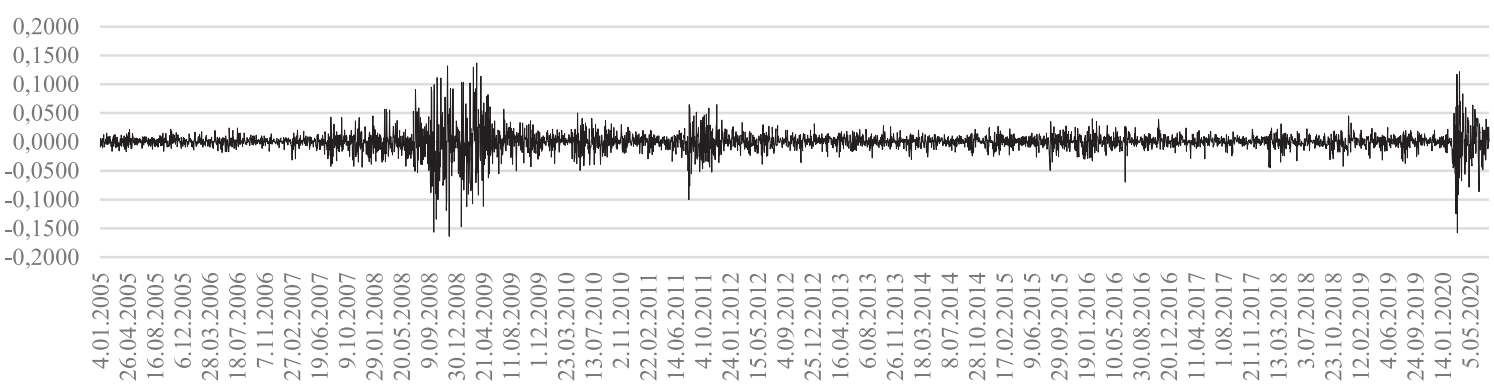

Health Care

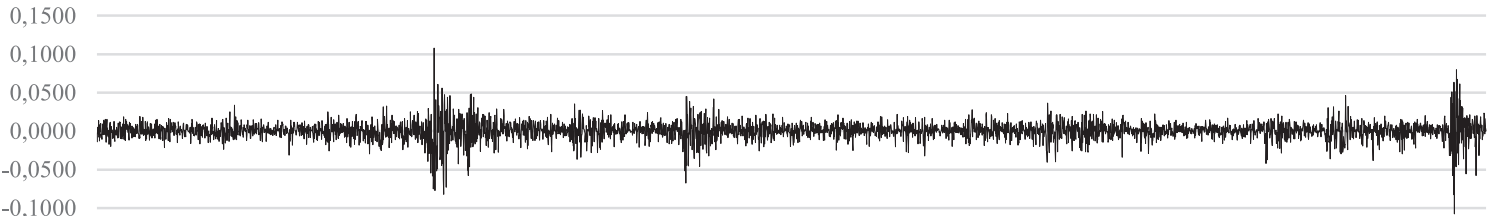

$-0,1500$

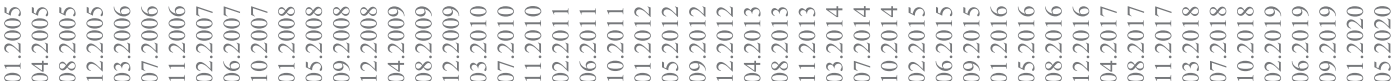

+

Industrials

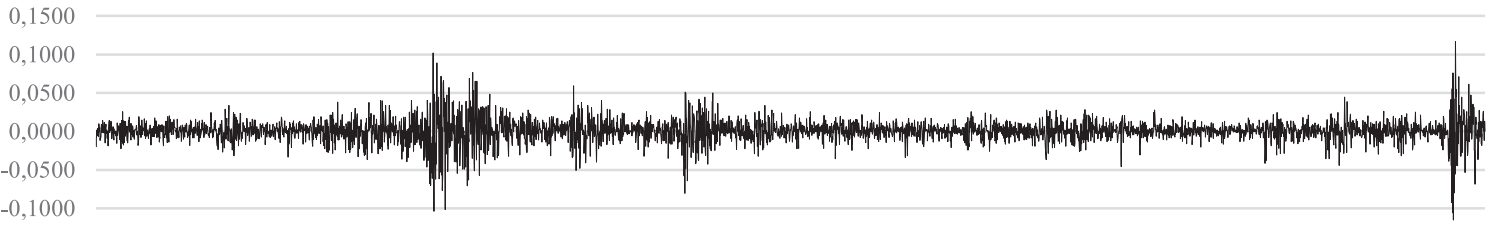

0,1500

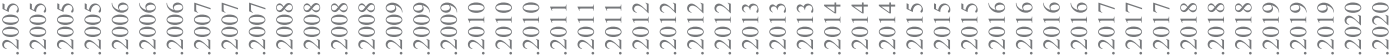

б

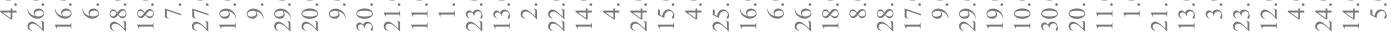

\section{Information Technology}

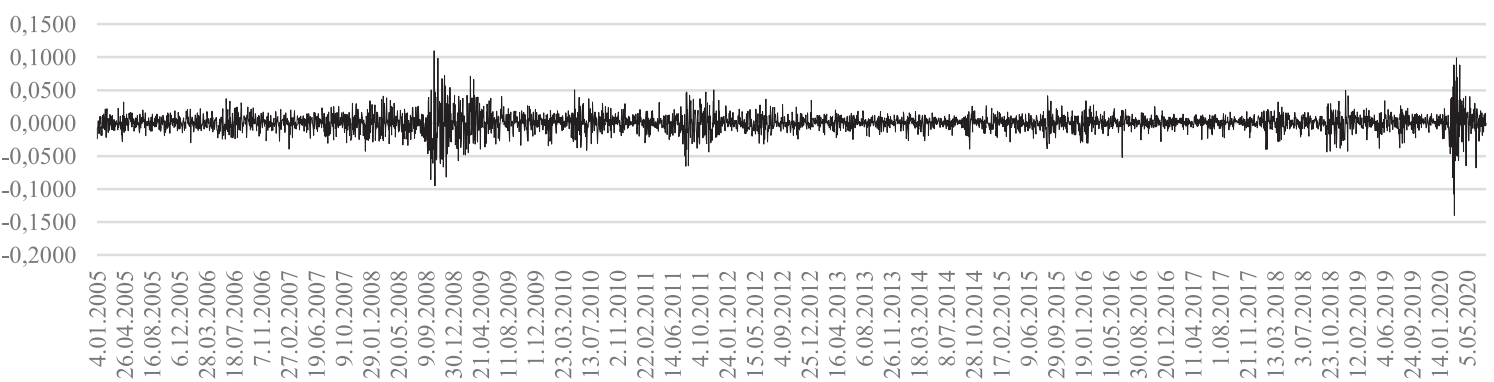




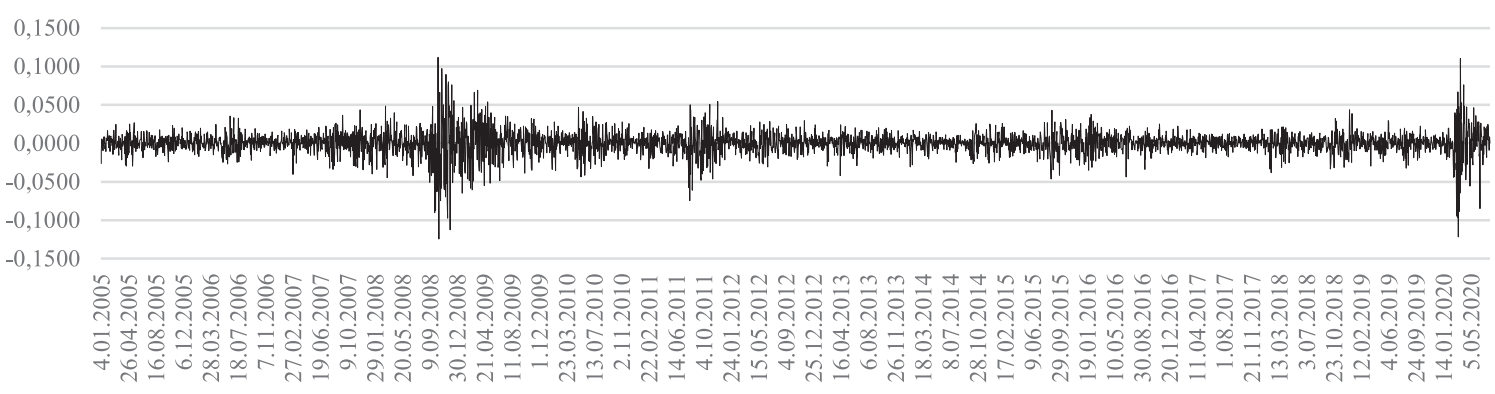

Real Estate

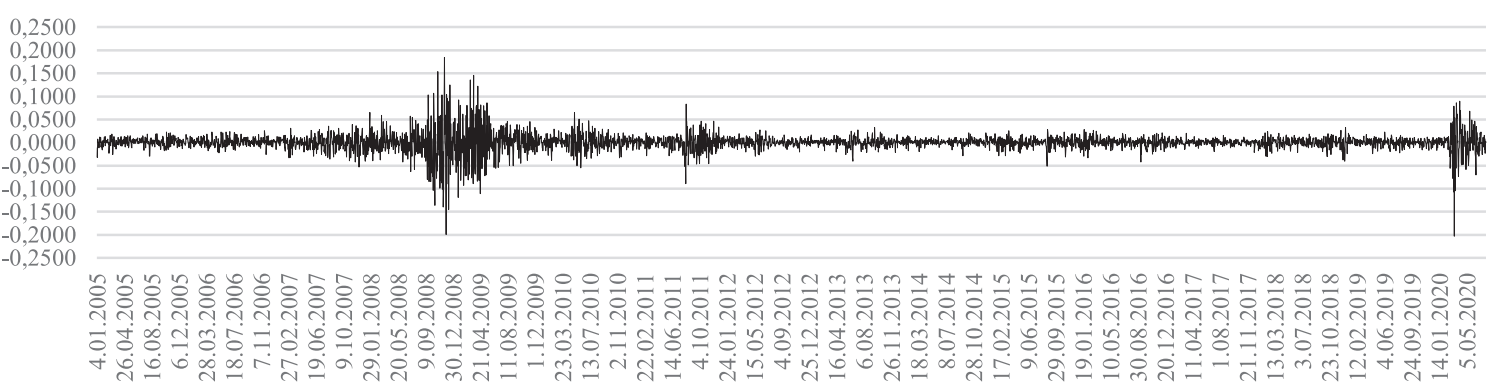

Utilities

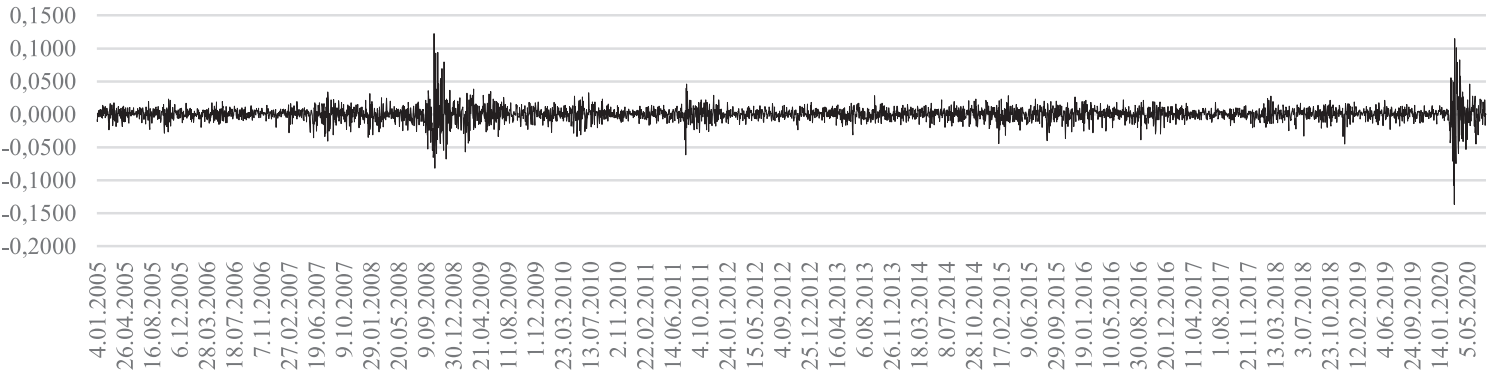

Figure 1: The return series of each S\&P 500 sector

In Figure 1, there are obvious fluctuations because of the mortgage crisis in 2008 in all return series of S\&P 500 sectors. Moreover, it is clear that there are high volatile periods similar to mortgage crisis periods for all graphs in 2020 due to the COVID-19 pandemic, as well. However, those fluctuations seem to higher than the mortgage crisis periods for most of the sectors (Consumer Discretionary, Consumer Staples, Energy, Health Care, Information Technology, Real Estate, Utilities). Thus, it can be said that there is a major impact of the COVID-19 pandemic on S\&P 500 sector returns. Therefore, it is needed to be investigated deeply.

For a detailed investigation, we employ the wavelet multi-scaling approach. In this analysis, we focus on the data period of September 2019 to July 2020 to unders- tand the impact of the COVID-19 pandemic better. The results of the analysis are presented in Figure 2.

In Figure 2, the beta coefficients for each S\&P 500 sector over the different timescales are given. The scales indicate different investment horizons, herein scale 1 , scale 2 , scale 3 , scale 4 , and scale 5 represent respectively a period of 2-4 days, 4-8 days, 8-16 days, 16-32 days, and 32-64 days. The results show that the systematic risks of each sector vary over the different timescales in the pandemic period. From scale 1 to scale 4 (towards low frequencies), communication services became more sensitive to the daily movements of the market, however, the sector's beta coefficient became lower than 1 again at scale 5 . Furthermore, while consumer discretionary, energy, financials, industrials, information technology, materials, and real 
estate sectors are sensitive to the daily movements of the market, consumer staples, health care, and utilities sectors are less sensitive during the pandemic period.

The systematic risk is a kind of aggregate risk for financial markets and impossible to completely avoid. Furthermore, it is an indicator of market risk and underlying other investment risks, such as sector risks. Investors should follow the fluctuations of systematic risk attentively because it is not predictable and manageable. It is expected that the systematic risk is higher in the financial crisis periods because of the rising uncertainty than the normal periods. Hence, the impact of the pandemic period as a financial crisis on different sectors should be examined deeply. The WPS approach might be applied to examine the change of volatility in betas (or systematic risks) over different timescales. For this aim, we generated the sector-based daily beta time series from May 2005 to July 2020 and used the data period of September 2019 to July 2020 to understand the effect of the COVID-19 pandemic better, as well.

In Figure 3, the plots demonstrate the WPS's for financial betas of each sector portfolio, i.e. how the variance of financial betas or its volatility changes over time for different frequencies. The horizontal axis in WPS plots indicates a time period while the vertical axis on the left side shows scales based on daily frequencies. The vertical axis on the right side demonstrates the wavelet power measured by volatility. On this axis, wavelet power is represented by colors and the red color corresponds to high power (volatility) whereas the blue one to low power (volatility). In the plots of WPS, the black contour lines show the $5 \%$ significance level based on Monte Carlo simulations. The shaded area below the thin black line refers to a kind of edge effect ${ }^{4}$.

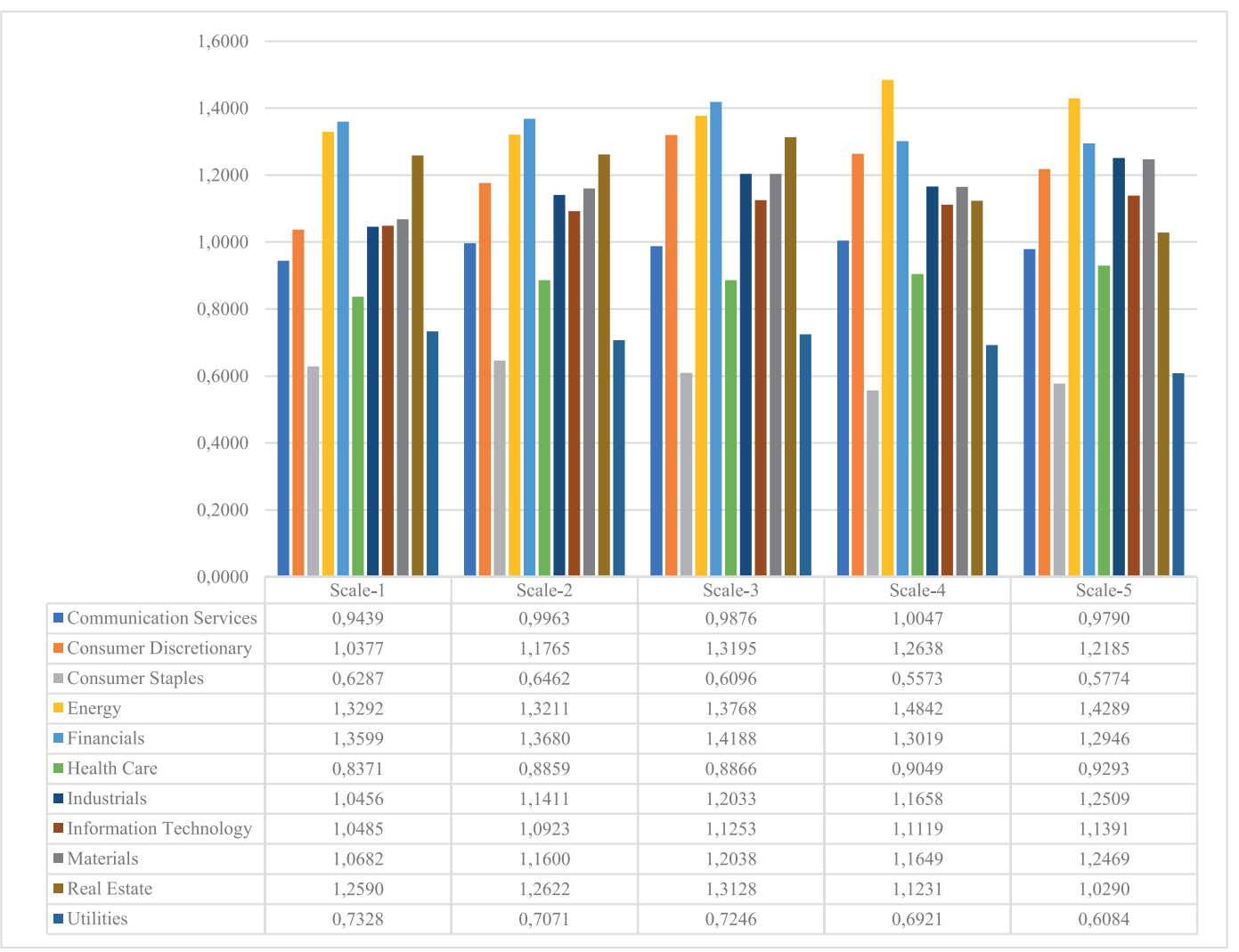

Figure 2: The beta coefficients for each S\&P 500 sector over the different timescales

\footnotetext{
${ }^{4}$ The CWT assumes that time series are cyclical but when we apply this assumption for finite-length time series, some problems emerge such as border distortions in wavelet analysis. Accordingly, the values of the transform at the beginning and the end of the time series might be inaccurately computed. A way in order to avoid this problem is to pad the ends of the series with zeros. However, zero-padding will induce discontinuities at the endpoints, particularly while moving towards lower frequencies (higher scales). This approach may also lead to uncertainty whether the variance or volatility as moving towards lower frequencies is actually declined or not. The variance may actually decrease or due to the zero values at the end of the transformed time series. Therefore, the shaded areas under the thin black line should be carefully interpreted not to make incorrect inferences (Jiang et al., 2015; Gallegati et al., 2014).
} 


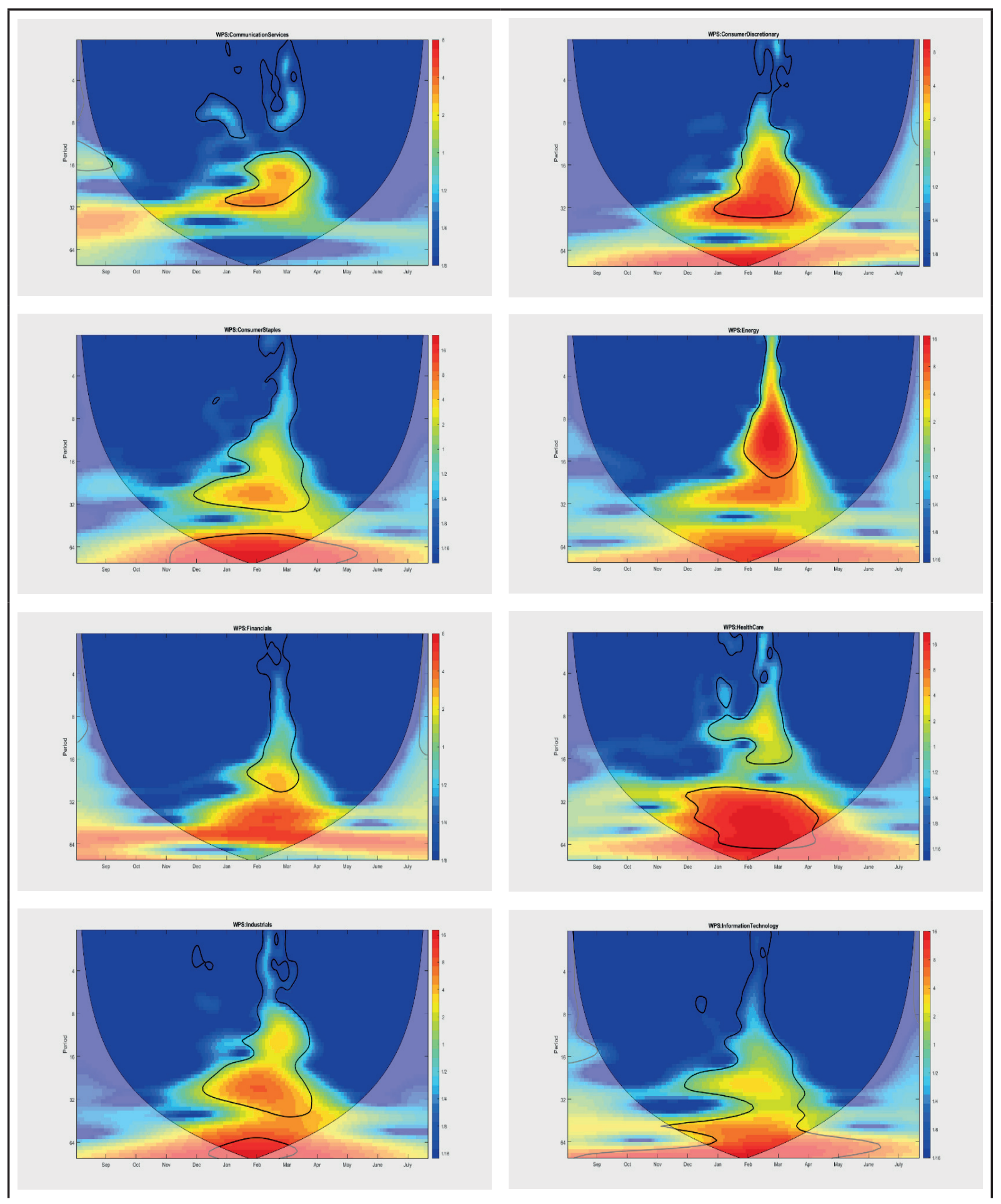




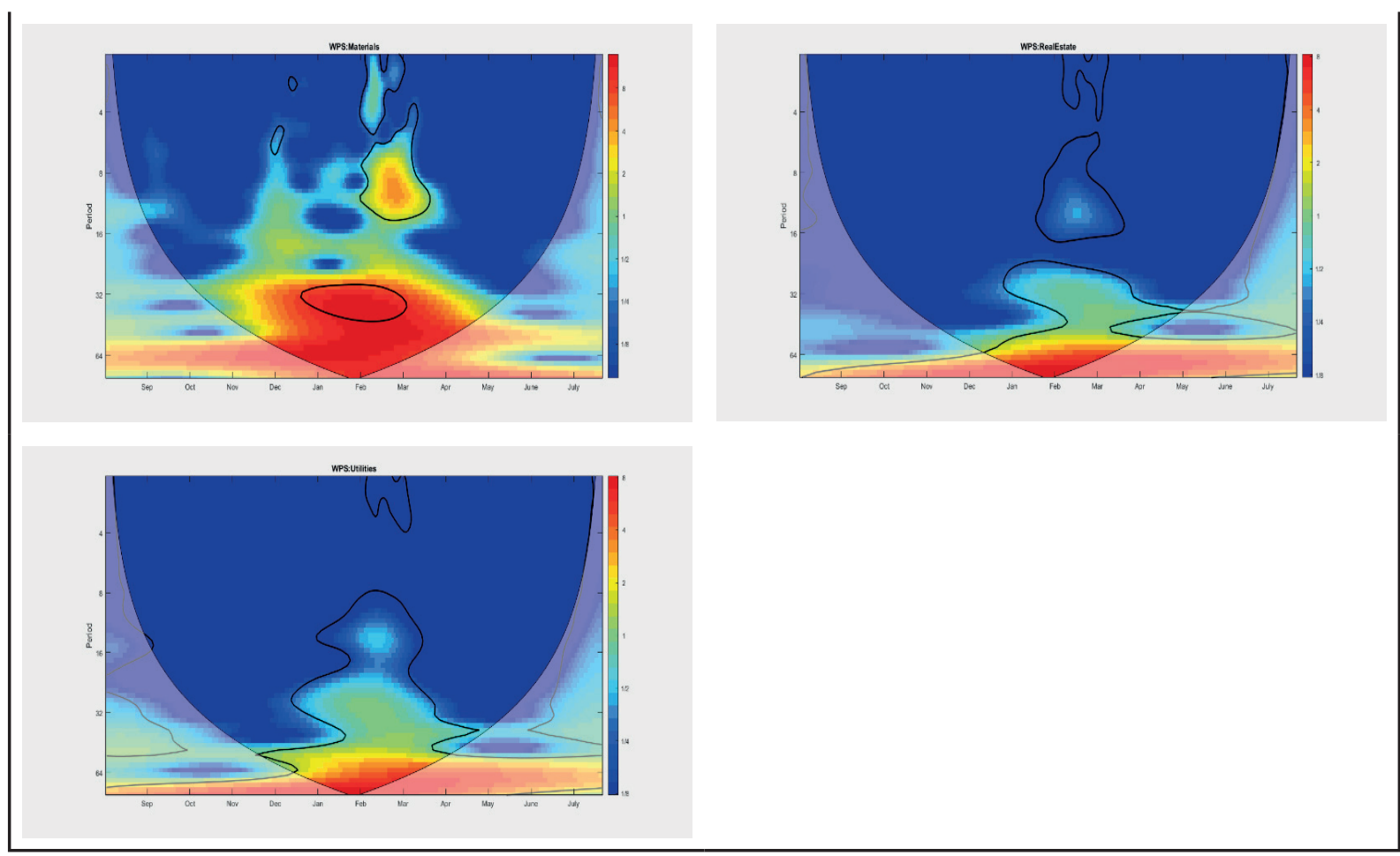

Figure 3: WPS's for financial betas of each sector portfolio

It is clear that there are significant volatility changes over different investment horizons for each S\&P 500 sector in the pandemic period. All significant volatility changes in sectors are observed from January to April. However, the impact of the pandemic on volatility differs by the sectors. There is high and significant volatility for energy sector at scale 3 (8-16 days). The investors who invested in that sector react to the pandemic for cycles of 8-16 days. High and significant volatilities can be observed at scale 4 (16-32 days) for communication services, consumer discretionary, and financials sectors. High and significant volatilities can be observed at scale 5 (32-64 days) for consumer staples, health care, industrials, information technology, materials, real estate and utilities sectors. The investors who invested in those sectors react to the pandemic for cycles of 32-64 days. Significant volatility of the systematic risk can be observed at all scales for consumer staples, health care, industrials, information technology, and real estate sectors. However, the level of volatility is quite low for the real estate sector at all scales except for scale 5 . In the health care sector, the level of volatility is quite high at scale 5 from January to April while it is not high at other scales. This means that the long-run risk level raised because of the pandemic for that sector. The reason for this finding might be the uncertainty of whether the healthcare system can handle the pandemic. It is expected that sectors with high debt ratios (Table 1) may cause investors to react with fear and panic. However, the findings indicate that there is no meaningful linkage between the average debt ratios and volatility of systematic risk during the pandemic period. Even though the energy sector has the lowest debt ratio, its volatility level of the systematic risk is high at some scales. Moreover, the reactions of investors to the pandemic are not symmetric because the volatility levels of systematic risks change over different time scales based on sectors.

In conclusion, it can be said that the source of high/ low volatile situations on systematic risk is irrational investors. Those results support the Prospect Theory by Kahneman and Tversky (1979). The theory states that there is an asymmetry of risk aversion in financial markets and investors react differently between potential losses and gains. Thereby, investment is dominated by the emotions of investors such as fear or greed (Sharpe et. al. 1999:144). The COVID-19 pandemic has created a kind of fear in financial markets and this situation caused fluctuations on systematic risk in different sectors.

\section{CONCLUSION}

In modern finance, investors are accepted to be rational. Most researchers examine this phenomenon 
for the near half-century. However, in the real world, this assumption is not valid. According to a branch of psychology known as cognitive psychology, which studies the capacity of human beings for perception and judgment, people do not appear to be consistent in how they treat economically equivalent choices when the choices are presented in significantly different contexts. Kahneman and Tversky (1979) argued the investors within the frame of cognitive psychology and they presented the Prospect Theory. The theory states that the irrational behavior of investors creates asymmetric market reactions such that people react differently between potential losses and potential gains. Therefore, according to the theory, when panic or fear occurs in the market, unexpected drops can be observed.

The Coronavirus Disease (COVID-19) is a potential crisis and a source of panic for financial markets. Especially, the lockdown decisions of many governments caused fear situations, and many companies faced with potential loss or bankruptcy. As a result of those circumstances, unexpected fluctuations occurred. It is expected that the systematic risks of various sectors are affected differently. In this study, we aim to examine the changing of S\&P500 sector portfolios' systematic risks and the volatility levels of them, over different time scales or investment horizons. For that purpose, we applied the wavelet multi-scaling approach and the wavelet power spectrum analysis, respectively. The dataset obtained for S\&P500 stock returns of eleven sectors includes the COVID-19 pandemic crisis, as well.

The results of the analysis can be discussed in three parts. (i) The systematic risks of each sector vary over the different timescales in the pandemic period. From high frequencies towards low frequencies, while some sectors are more sensitive to the daily movements of the market, some others are less sensitive in the pandemic period. This result shows that the response speed of sectors varies due to their different structures. (ii) Consumer discretionary, energy, financials, industrials, information technology, materials, and real estate sectors are sensitive to the daily movements of the market during the pandemic period. (iii) The volatility levels of systematic risks of each sector change over different investment horizons during the pandemic period. In general, it is observed that the level of volatility rises from high frequencies to low frequencies. The reason for this finding might be that investors in the S\&P 500 ignore the COVID-19 at the beginning. Moreover, there is no relationship between high average debt ratios and the volatility of systematic risks during the pandemic period. The reactions of investors to the pandemic are asymmetric and this might be an indicator of the existence of irrational investors.

In conclusion, investors should consider the structure of sectors in their investment strategies in periods of crisis. They should also follow carefully the fluctuations in systematic risk which is not predictable and manageable to reduce uncertainty in their investments. However, the findings indicate the existence of irrational investors in the market. Since they trade with emotions such as fear and panic during the crisis period, this creates high volatility in systematic risk. These results provide some evidence on behalf of the Prospect Theory. 


\section{REFERENCES}

Aguiar-Conraria, L. and Soares, M. J. (2011), “Oil and the macroeconomy: using wavelets to analyze old issues", Empirical Economics, Vol. 40 No. 3, pp. 645-655.

Aloui, C. and Hkiri, B. (2014), “Co-movements of GCC emerging stock markets: New evidence from wavelet coherence analysis", Economic Modelling, Vol. 36, pp. 421-431.

Altarturi, B. H., Alshammri, A. A., Hussin, T. M. T. T. and Saiti, B. (2016), “Oil price and exchange rates: A wavelet analysis for organisation of oil exporting countries members", International Journal of Energy Economics and Policy, Vol. 6 No. 3, pp. 421-430.

Aygoren, H. (2008) "Istanbul Menkul Kiymetler Borsasinin fractal analizi", Dokuz Eylul Universitesi Iktisadi Idari Bilimler Fakultesi Dergisi, Vol. 23 No. 1, pp. 125-134.

Bernard, V. L., Botosan, C. A. and Phillips, G. D. (1994), “Challenges to the Efficient Market Hypothesis: Limits to the Applicability of Fraud-on-the-Market Theory", Nebraska Law Review, Vol. 73 No. 4, pp. 781-811.

Black, F. (1986), “Noise”, The Journal of Finance, Vol. 41 No. 3, pp. 528-543.

Brailsford, T. J. and Faff, R. W. (1997), "Testing the conditional CAPM and the effect of intervaling: a note", Pacific-Basin Finance Journal, Vol. 5 No.5, pp. 527-537.

Capobianco, E. (2004), "Multiscale analysis of stock index return volatility", Computational Economics, Vol. 23 No.3, pp. 219237.

Cohen, K. J. (1986), The microstructure of securities markets, Prentice Hall, Sydney.

Connor, J. and Rossiter, R. (2005), "Wavelet transforms and commodity prices" Studies in Nonlinear Dynamics and Econometrics, Vol. 9 No.1, pp. 1-22.

Cornish, C. R., Bretherton, C. S. and Percival, D. B. (2006), “Maximal overlap wavelet statistical analysis with application to atmospheric turbulence" Boundary-Layer Meteorology, Vol. 119 No. 2, pp. 339-374.

Crowley, P. M. (2007), "A guide to wavelets for economists" Journal of Economic Surveys, Vol. 21 No.2, pp. 207-267.

Crowley, P. M. and Lee, J. (2005), “Decomposing the co-movement of the business cycle: a time-frequency analysis of growth cycles in the euro area", working paper, Bank of Finland Research Discussion Paper No:12, Finland.

Fama, E. F. (1970), "Efficient capital markets: A review of theory and empirical work" The Journal of Finance, Vol. 25 No. 2, pp. 383-417.

Gallegati, M., Gallegati, M., Ramsey, J. B. and Semmler, W. (2006), "The decomposition of the Inflation-unemployment relationship by time scale using wavelets" Contributions to Economic Analysis, Vol. 277, pp. 93-111.

Gallegati, M., Gallegati, M., Ramsey, J. B. and Semmler, W. (2014), "Does productivity affect unemployment? A time-frequency analysis for the US", Wavelet Applications in Economics and Finance, Springer, Cham, pp. 23-46.
Gençay, R., Gradojevic, N., Selçuk\|l, F. and Whitcher, B. (2010), "Asymmetry of information flow between volatilities across time scales", Quantitative Finance, Vol. 10 No. 8, pp. 895-915.

Gençay, R., Selçuk, F., and Whitcher, B. (2001), "Scaling properties of foreign exchange volatility", Physica A: Statistical Mechanics and its Applications, Vol. 289 No. 1-2, pp. 249-266.

Gençay, R., Selçuk, F., and Whitcher, B. (2003), "Systematic risk and timescales" Quantitative Finance, Vol. 3 No.2, pp. 108-116.

Gençay, R., Selçuk, F. and Whitcher, B. (2005), "Multiscale systematic risk", Journal of International Money and Finance, Vol. 24 No.1, pp. 55-70.

Gençay, R., Selçuk, F. and Whitcher, B. J. (2002), An introduction to wavelets and other filtering methods in finance and economics, Academic Press, San Diego, CA.

Glen, P. J. (2005), “Efficient Capital Market Hypothesis, Chaos Theory, and the Insider Filing Requirements of the Securities Exchange Act of 1934: The Predictive Power of Form 4 Filings", Fordham Journal of Corporate and Financial Law, Vol. 11 No.1, pp. 85-114.

Griggs Jr, F. S. (2002), "No stone unturned-forecasting revisited" AACE International Transactions, Vol. RI91-RI94.

Grinsted, A., Moore, J. C. and Jevrejeva, S. (2004), “Application of the cross wavelet transform and wavelet coherence to geophysical time series", Nonlinear Processes in Geophysics, Vol. 11, pp. 561-566.

Grossman, S. J. and Stiglitz, J. E. (1980), “On the impossibility of informationally efficient markets", The American Economic Review, Vol. 70 No. 3, pp. 393-408.

Habimana, O. (2019), "Wavelet multiresolution analysis of the liquidity effect and monetary neutrality", Computational Economics, Vol. 53 No. 1, pp. 85-110.

Handa, P., Kothari, S. P. and Wasley, C. (1989), "The relation between the return interval and betas: Implications for the size effect", Journal of Financial Economics, Vol. 23 No. 1, pp. 79-100.

Handa, P., Kothari, S. P. and Wasley, C. (1993), "Sensitivity of multivariate tests of the capital asset-pricing model to the return measurement interval", The Journal of Finance, Vol. 48 No. 4, pp. 1543-1551.

In, F. and Kim, S. (2013), An introduction to wavelet theory in finance: a wavelet multiscale approach, World Scientific Publishing, Singapure.

Jarrett, J. E. and Kyper, E. (2006), “Capital market efficiency and the predictability of daily returns", Applied Economics, Vol. 38 No. 6, pp. 631-636.

Jensen, M. C. (1978), "Some anomalous evidence regarding market efficiency", Journal of Financial Economics, Vol. 6 No. 2/3, pp. 95-101.

Jiang, C., Chang, T. and Li, X. L. (2015), "Money growth and inflation in China: new evidence from a wavelet analysis", International Review of Economics and Finance, Vol. 35, pp. 249-261. 
Kahneman D. and Tversky A. (1979), "Prospect theory: An analysis of decision under risk", Econometrica, Vol. 47, pp. 263-291.

Kahneman, D. and Riepe, M. W. (1998), "Aspects of investor psychology", Journal of Portfolio Management, Vol. 24 No. 4, pp. 52-65.

Karp, A. and Van Vuuren, G. (2019), "Investment implications of the fractal market hypothesis", Annals of Financial Economics, Vol. 14 No. 01, pp. 1-27.

Kim, S. and In, F. H. (2003), "The relationship between financial variables and real economic activity: evidence from spectral and wavelet analyses", Studies in Nonlinear Dynamics and Econometrics, Vol. 7 No. 4, pp. 1-16.

Levhari, D. and Levy, H. (1977), "The capital asset pricing model and the investment horizon", The Review of Economics and Statistics, Vol. 59 No. 1, pp. 92-104.

Mallat, S. G. (1989), "A theory for multiresolution signal decomposition: the wavelet representation", IEEE Transactions on Pattern Analysis and Machine Intelligence, Vol. 11 No. 7, pp. 674-693.

Masset, P. (2015), "Analysis of Financial Time Series Using Wavelet Methods", Handbook of Financial Econometrics and Statistics, Springer, USA, pp. 539-573.

Percival, D. B. and Mofjeld, H. O. (1997), "Analysis of subtidal coastal sea level fluctuations using wavelets", Journal of the American Statistical Association, Vol. 92 No. 439, pp. 868-880.

Percival, D. and Walden, A. (2000) Wavelet methods for time series analysis. Cambridge University Press, Cambridge, UK.

Ramsey, J. B. (1999), "The contribution of wavelets to the analysis of economic and financial data", Philosophical Transactions of the Royal Society of London. Series A:Mathematical, Physical and Engineering Sciences, Vol. 357 No. 1760, pp. 2593-2606.
Ramsey, J. B. (2002), “Wavelets in economics and finance: past and future", Studies in Nonlinear Dynamics and Econometrics, Vol. 6 No. 3, pp. 1-27.

Ramsey, J. B. and Lampart, C. (1998), “Decomposition of economic relationships by timescale using wavelets", Macroeconomic Dynamics, Vol. 2 No. 1, pp. 49-71.

Robinson, K. K. (2013), “Technical Analysis: Does Recent Market Data Substantiate the Efficient Market Hypothesis?" Available at SSRN 3093251.

Rua, A. and Nunes, L. C. (2009), "International comovement of stock market returns: A wavelet analysis", Journal of Empirical Finance, Vol. 16 No. 4, pp. 632-639.

Saiti, B., Bacha, O. I. and Masih, M. (2016), "Testing the conventional and Islamic financial market contagion: evidence from wavelet analysis", Emerging Markets Finance and Trade, Vol. 52 No. 8, pp. 1832-1849.

Schleicher, C. (2002), "An introduction to wavelets for economists", working paper, Bank of Canada, Canada.

Sharpe, W. F., Alexander, G. J. and Bailey, J.V. (1999), Investments, Prentice-Hall, USA.

Shik Lee, H. (2004), "International transmission of stock market movements: a wavelet analysis", Applied Economics Letters, Vol. 11 No. 3, pp. 197-201.

Shiller, R. J., Fischer, S. and Friedman, B. M. (1984), "Stock prices and social dynamics", Brookings Papers on Economic Activity, Vol. 1984 No. 2, pp. 457-510.

Shleifer, A. (2000), Inefficient Markets: An Introduction to Behavioral Finance, 1st ed., Oxford University Press, USA.

Xu, F., Lai, Y. and Shu, X. B. (2018), "Chaos in integer order and fractional order financial systems and their synchronization", Chaos, Solitons and Fractals, Vol. 117, pp. 125-136. 